Article

\title{
Effects of Wheat-Maize Intercropping on Population Dynamics of Wheat Aphids and Their Natural Enemies
}

\author{
Junhe Liu ${ }^{1}$, Yan Yan ${ }^{2}$, Abid Ali $^{3}$ (D), Ningtao Wang ${ }^{4}$, Zihua Zhao ${ }^{5, *}$ and Mingfu Yu ${ }^{1, *}$ \\ 1 College of Biological Engineering, Huanghuai University, Zhumadian 463000, China; \\ liujunhe@huanghuai.edu.cn \\ 2 Landscape Research Institutes of Zhumadian, Zhumadian 463000, China; yan_liujunhe@126.com \\ 3 Department of Entomology, University of Agriculture, Faisalabad 38040, Pakistan; abid_ento74@yahoo.com \\ 4 Department of Biostatistics, School of Public Health, University of Texas Health Science Center at Houston, \\ Houston, TX 77030, USA; Ningtao.wang@uth.tmc.edu \\ 5 Department of Entomology, College of Plant Protection, China Agricultural University, Beijing 100193, China \\ * Correspondence: zhzhao@cau.edu.cn (Z.Z.); mingfuyu@126.com (M.F.); Tel.: +86-010-6273-3000 (Z.Z.); \\ +86-0396-2853-596 (M.F.)
}

Received: 22 June 2017; Accepted: 1 August 2017; Published: 7 August 2017

\begin{abstract}
To study the effects of wheat-maize intercropping on the population dynamics of wheat aphids and their natural enemies, wheat-maize intercropping patterns were divided into four levels: $8: 2,6: 2$, and 4:2 intercropping, and monoculture wheat. The results showed that as the wheat coverage rate decreased, the quantities of immigrating winged aphids and their natural enemies significantly differed; the population densities of the natural enemies of wheat aphids continuously rose and reached the highest levels in the 4:2 intercropping. During the stable periods, the maximum population density of wheat aphids was the highest in monoculture wheat. With a reduction in the wheat coverage ratio, the maximum population density of wheat aphids showed a decreasing trend. The control imposed by predatory natural enemies in intercropped wheat was higher than that in monoculture wheat; it was strongest in the 8:2 intercropping and the lowest in wheat monoculture. With an increase in the proportion of wheat, the parasitism rate of parasitic wasps increased gradually and reached the highest level in 4:2 intercropping. The effect of host density on hyperparasitism was significant in the intercropped wheat. The intercropping pattern had a great effect on the wheat aphids' natural enemies. In different agricultural landscapes, the diversity of wheat aphids' natural enemies differed significantly between intercropped wheat and monoculture wheat; in the heterogeneous landscape, the natural enemy diversity was highest in intercropped wheat, and it was far higher than that in the other wheat cultivation patterns. The natural enemy diversity was also slightly different between monoculture wheat in the heterogeneous landscape and intercropped wheat in the homogeneous agricultural landscape.
\end{abstract}

Keywords: wheat aphids; natural enemies; intercropping; population dynamics

\section{Introduction}

Intercropping is a method of increasing the spatial heterogeneity of habitats by promoting fragmentation at the field level. In the Chinese traditional agricultural system, intercropping can make full use of land resources to increase production, which has a great effect on the distribution of the agricultural landscape. However, there are very few studies reporting on interaction of intercropping with pests and natural enemies. Many studies indicated that intercropping can improve the natural population and strengthen the biological control effect [1-6]. 
Intercropping can reduce the number of pests due to a decrease of immigration, survival rate, and the decrease of fecundity [7]. Intercropping causes changes in the microclimate of the field (e.g., temperature and humidity), which may affect the growth and reproduction of various insects [8]. Natural diversity plays an important role in maintaining the stability of biological control while maintaining the higher diversity of the agricultural landscape $[9,10]$. In conclusion, many studies have been conducted on the biological control of intercropping, some of which have been successful and some failed.

As a traditional method to increase the production of farmland, recently wheat-maize intercropping has been widely used in Northwestern China. The functions of the intercropping system depend on spatiotemporal characteristics, heredity, and the regularity of pest insect distributions in each crop [11]. Muthukumar et al. [11] hypothesized that intercropping could increase the quantity of insects natural enemies and hence inhibit damage by pests. Crops in intercropping systems were less susceptible than those in monocultures to the occurrence of pest insects [12]. The intercropping of multiple plants may provide a better microenvironment to inhibit the growth of pest insects.

Increasing studies have considered the inhibition of pest insects and the protection of pests' natural enemies in the many types of wheat intercropping, including wheat-rape intercropping [3,13-16], wheat-garlic intercropping [12-21], wheat-alfalfa intercropping [12], and wheat-canopy intercropping [22]. All of the intercropping systems increased the quantity of wheat aphids' major natural enemies and the diversities of both predatory and parasitic natural enemies during the outbreak period of wheat aphids $[11,18,19]$. However, according to the insect landing hypothesis [17], the quantity of immigrating winged aphids in intercropped wheat is much larger than that in monoculture wheat. Therefore, it is still unresolved whether intercropping can truly increase the mitigation of wheat aphids. In particular, there is a lack of detailed reports about the population size of early-immigrating winged aphids, which is a well-known factor in the ultimate damage caused by these insects [23]. Zhou et al. [16] studied wheat aphid population growth and decline under different intercropping patterns, but failed to explore the interactions among the intercropped crops, wheat aphids, and their natural enemies. Studying the effect of intercropping on wheat aphids and their natural enemies can provide novel and efficient approaches to control wheat aphid occurrence.

This study utilized three of the most common wheat aphid species, i.e., Macrosiphum avenae, Schizaphis graminum, and Rhopalosiphum padi, and their corresponding natural enemies in wheat-maize intercropped crops on the Yinchuan Plain. Four intercropping planting patterns were designed to address the following questions: (1) What is the wheat aphid occurrence regularity in the intercropped crops? In particular, what are the differences among the four intercropping planting patterns in the period of winged aphids in wheat? (2) How can the interactions among the intercropped crops, wheat aphids, and their natural enemies be quantified? (3) What is the optimal intercropping pattern facilitating an increase in the population of natural enemies?

\section{Materials and Methods}

\subsection{Field Area and Experimental Design}

Experiments were conducted repeatedly during the summer over three growing seasons each year from April to July in 2012, 2013, and 2014 in Zhangzheng township ( $38^{\circ} 25^{\prime} 45^{\prime \prime} \mathrm{N}, 106^{\circ} 22^{\prime} 21^{\prime \prime}$ E), which is one of the main wheat-producing areas on the Yinchuan Plain of the Ningxia autonomous region in China. The total experimental field area was subdivided into $45 \times 45 \mathrm{~m}$ using $4 \times 4$ Latin squares design (LSD) where all four wheat-maize intercropping patterns (i.e., 8:2, 6:2, and 4:2 intercropping, and monoculture wheat) were evenly distributed throughout the field area (Table 1). Here, ratios represent the percent area distribution between two crops in the $5 \times 5 \mathrm{~m}$ area for each cell (plot) as shown in Table 1. The edge effect (buffer area) was $5 \mathrm{~m}$ from all sides of each plot. 
Table 1. The experimental design of the $4 \times 4$ Latin square. Each cell is $5 \times 5 \mathrm{~m}^{2}$.

\begin{tabular}{cccc}
\hline Wheat:maize $=8: 2$ & Wheat:maize $=6: 2$ & Wheat:maize $=4: 2$ & Monoculture wheat \\
Wheat:maize $=6: 2$ & Wheat:maize $=4: 2$ & Monoculture wheat & Wheat:maize $=8: 2$ \\
Wheat:maize $=4: 2$ & Monoculture wheat & Wheat:maize $=8: 2$ & Wheat:maize $=6: 2$ \\
Monoculture wheat & Wheat:maize $=8: 2$ & Wheat:maize $=6: 2$ & Wheat:maize $=4: 2$ \\
\hline
\end{tabular}

\subsection{Sampling}

In this study, the population quantities of (1) wheat aphids, including M. avenae, S. graminum, and R. padi, (2) primary parasitoids, including Aphidius avenae and Aphidius gifuensis, (3) hyperparasitoids, including Pachyneuron aphidis and Alloxysta sp., and (4) a variety of predatory natural enemies, were observed three times per year from 5 to 25 May during the peak in aphid populations by both visual observation and hand collection.

At each site, five randomly-selected points were used for insect sampling in the wheat fields [20]. One hundred straws were randomly selected at each point, and 500 straws were, thus, screened per site. The density of wheat aphids was calculated as individuals per 100 straws.

The aphids were collected and taken to a laboratory for rearing. Aphids that died during the rearing were dissected to determine whether they were parasitized. All mummies were stored individually in gelatin capsules until the emergence of adult parasitoids. The gelatin capsules were kept in test tubes sealed with a damp cotton plug and placed in a climate chamber at $20{ }^{\circ} \mathrm{C}$ with $14 \mathrm{~h}$ light and $10 \mathrm{~h}$ darkness. The gelatin capsules with mummies were examined twice daily for the first month for the emergence of adults and once every two days in the following month. Mummies from which a parasitoid had not emerged for two months were dissected to examine the cause and were classified as either aestivating or dead [20,24]. All parasitoids and hyperparasitoids were identified by species. Parasitism (Nparasitoids / (Naphids + Nparasitoids)), i.e., the proportion of wheat aphids parasitized by parasitic wasps, and hyperparasitism (Nhyperparasitoids /(Nparasitoids + Nhyperparasitoids)) were then calculated $[25,26]$.

Brewer and Elliott (2004) classified all leaf-dwelling predators as specialists and all ground-dwelling predators as generalists [27]. Therefore, we used a sweep net method to collect specialist predators and a pitfall trap method to collect generalist predators. Sweep nets were used to collect specialist predators on 10,15, and 20 May each year. A standard sweep involved moving the open net in a semi-circle, and the sweep net was emptied every 10 strokes in the five-point random sample. At each site, a total of 50 sweeps were conducted, and the population density of specialist predators was calculated as the number of individuals per point. All captured insects were killed and preserved in $80 \%$ ethanol. At the same time, pitfall traps were employed to capture ground-dwelling generalist predators at the points selected for the five-point random sample. Pitfall traps consisted of $450 \mathrm{~mL}$ plastic cups dug down with the opening level to the ground and filled with $80 \mathrm{~mL}$ of $33 \%$ ethylene glycol. At each point, the distances between the traps were kept below $1 \mathrm{~m}$. Traps were placed in the field from 5 to 15 May each year to collect generalist predators continuously and were changed every five days. The activity density of generalist predators was calculated as the number of individuals per point [28]. All adult generalist and specialist predators were identified by species. The predator-prey ratio (Npredators/Naphids) was then calculated separately for generalist and specialist predators, where Npredators and Naphids represent the population densities of predators and cereal aphids, respectively. We observed the population density of wheat aphids and natural enemies while considering the immigration periods (time period in which wheat aphids enter the field), growth periods (time period in which aphids reproduce in the field), and stable periods (time period in which aphids remain stable in the field) [29]. 


\subsection{Statistical Methods}

To normalize the quantitative variables, we preprocessed the number of aphids per 100 straws and the parasitism rate using the arcsine function. Linear regression was then performed for both the number of aphids per 100 straws and the parasitism rate for the four intercropping patterns. The F-test in one-way ANOVA was implemented to detect differences among the intercropping patterns. The Duncan method was performed to correct for multiple comparisons among the different experimental sites. The threshold of the significance level was 0.05 for all tests.

\section{Results}

\subsection{The Immigration Period}

As the wheat coverage rate decreased, the quantities of immigrating M. avenae, S. graminum, and overall wheat aphids gradually increased and reached their maximums in the 4:2 intercropping. In addition, $R$. padi reached a maximum immigration quantity in the 6:2 intercropping (Figure 1). Meanwhile, with a decrease in the wheat coverage ratio, the population densities of all four kinds of wheat aphids' major natural enemies, i.e., monophagous, oligophagous, polyphagous, and omnivorous predators, gradually increased and reached their maximums in the 4:2 intercropping (Figure 1).
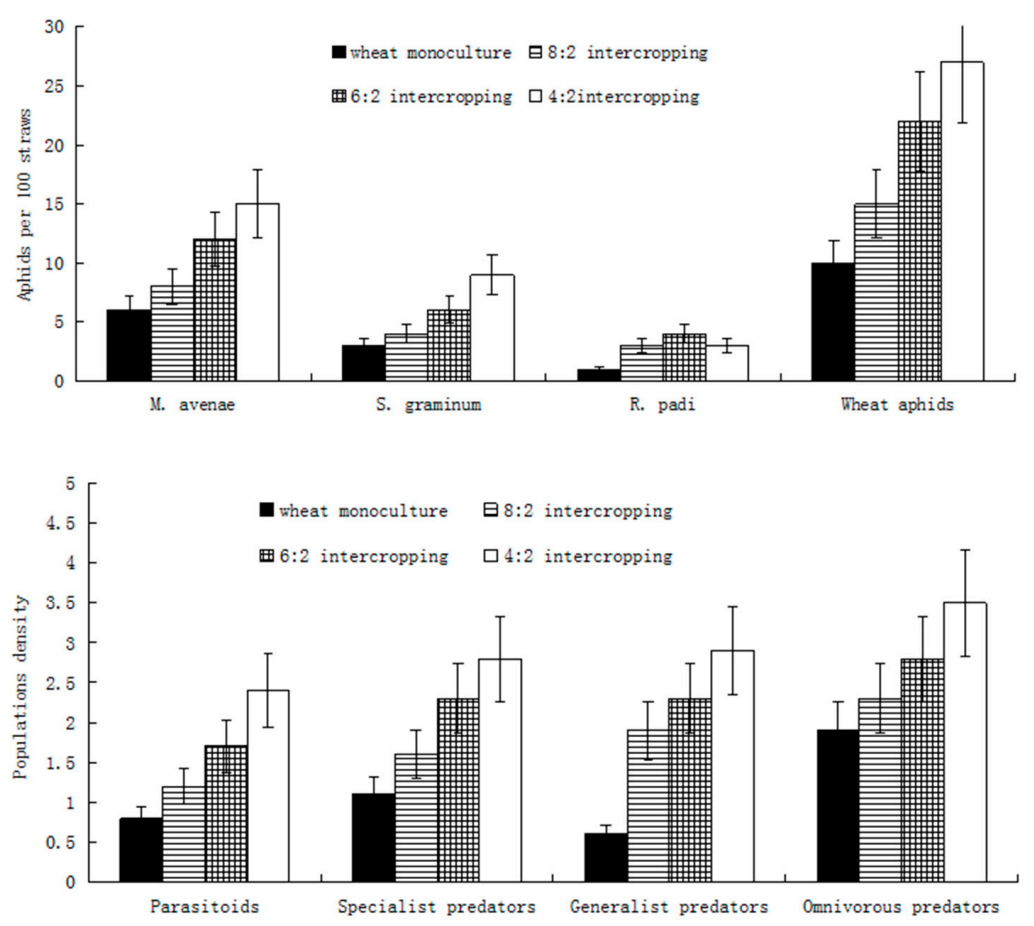

Figure 1. Population dynamics of wheat aphids and their natural enemies under different wheat intercropping patterns during the immigration periods.

\subsection{The Growth Period}

In contrast to the regularity of the quantity of immigrating winged aphids, the population growth rates of M. avenae, S. graminum, and overall wheat aphids gradually increased with an increase in the wheat coverage ratio and reached their maximums in the wheat monoculture. In addition, $R$. padi reached its maximum population growth rate in the 6:2 intercropping (Figure 2). During the growth period, all four kinds of wheat aphids' major natural enemies reached their maximum growth rates in the 8:2 intercropping. The monophagous, polyphagous and omnivorous predators reached their minimum growth rates in the wheat monoculture; the oligophagous predators reached their minimum growth rate in the 4:2 intercropping (Figure 2). 

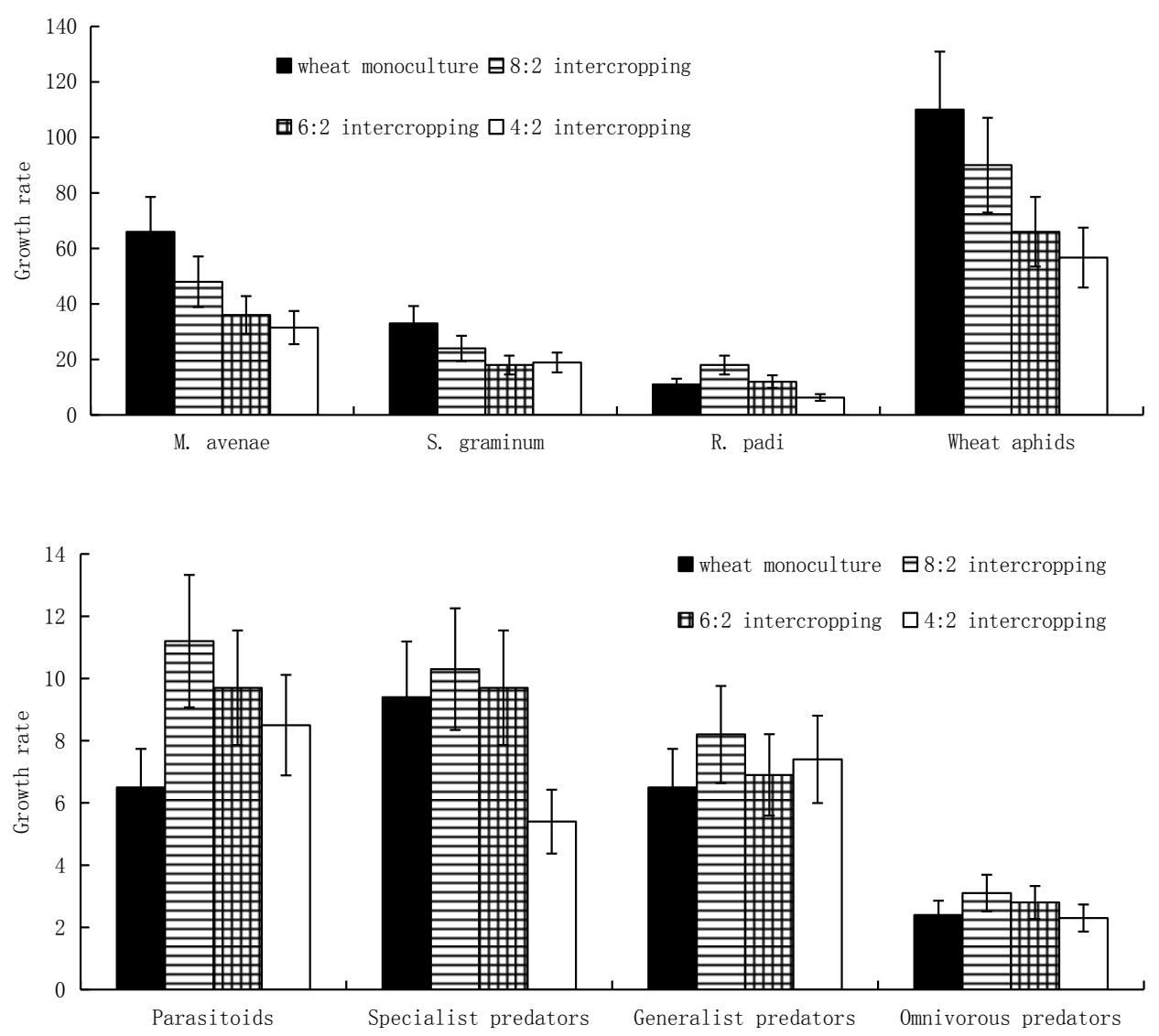

Figure 2. Population dynamics of wheat aphids and their natural enemies under different wheat intercropping patterns during the population's growth periods.

\subsection{The Stable Period}

During the stable period of the aphid populations, the population densities of M. avenae, S. graminum, and overall wheat aphids gradually increased with an increase in the wheat coverage ratio and reached their maximums in the wheat monoculture. In addition, R. padi reached its maximum population density in the 8:2 intercropping. Meanwhile, with a decrease in the wheat coverage ratio, the population densities of all four kinds of aphids' major natural enemies gradually increased and reached their maximums in the 4:2 intercropping (Figure 3).

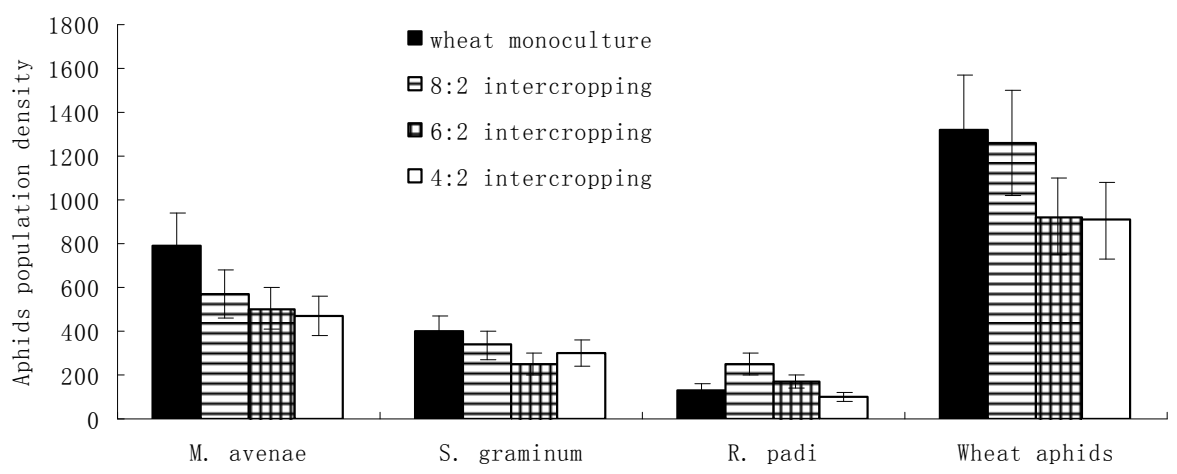

Figure 3. Cont. 


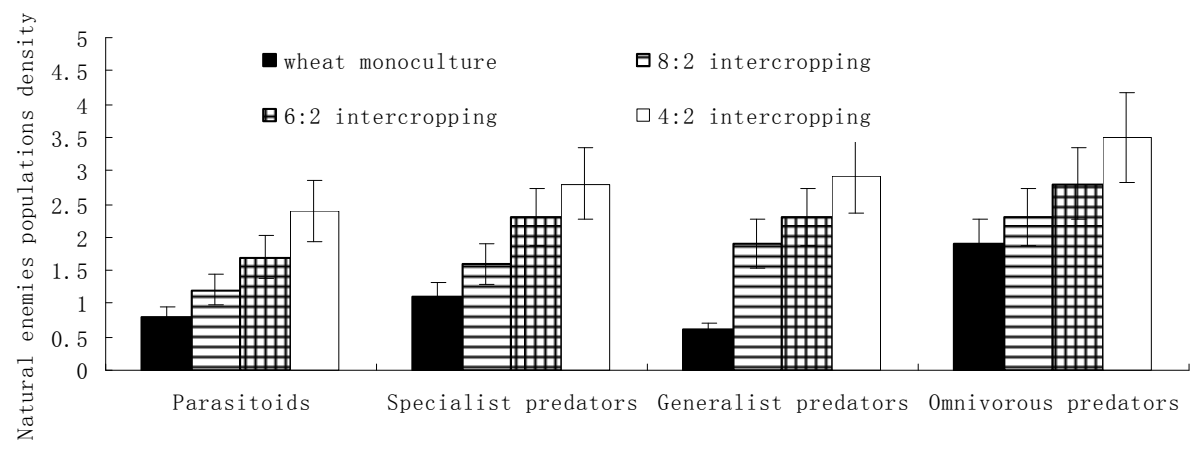

Figure 3. Population dynamics of wheat aphids and their natural enemies under different wheat intercropping patterns during the population's stable periods.

\subsection{Control of Wheat Aphids' Natural Enemies}

The diversity levels of wheat aphids' natural enemies and the parasitism rates of parasitoids gradually increased with a decrease in the wheat coverage ratio and reached their maximums in the 4:2 intercropping during both the growth and the stable periods. The abundance levels of natural enemies and the control rates of parasitoids reached their maximums in the 8:2 intercropping and minimums in monoculture wheat during both the growth and the stable periods (Figure 4).
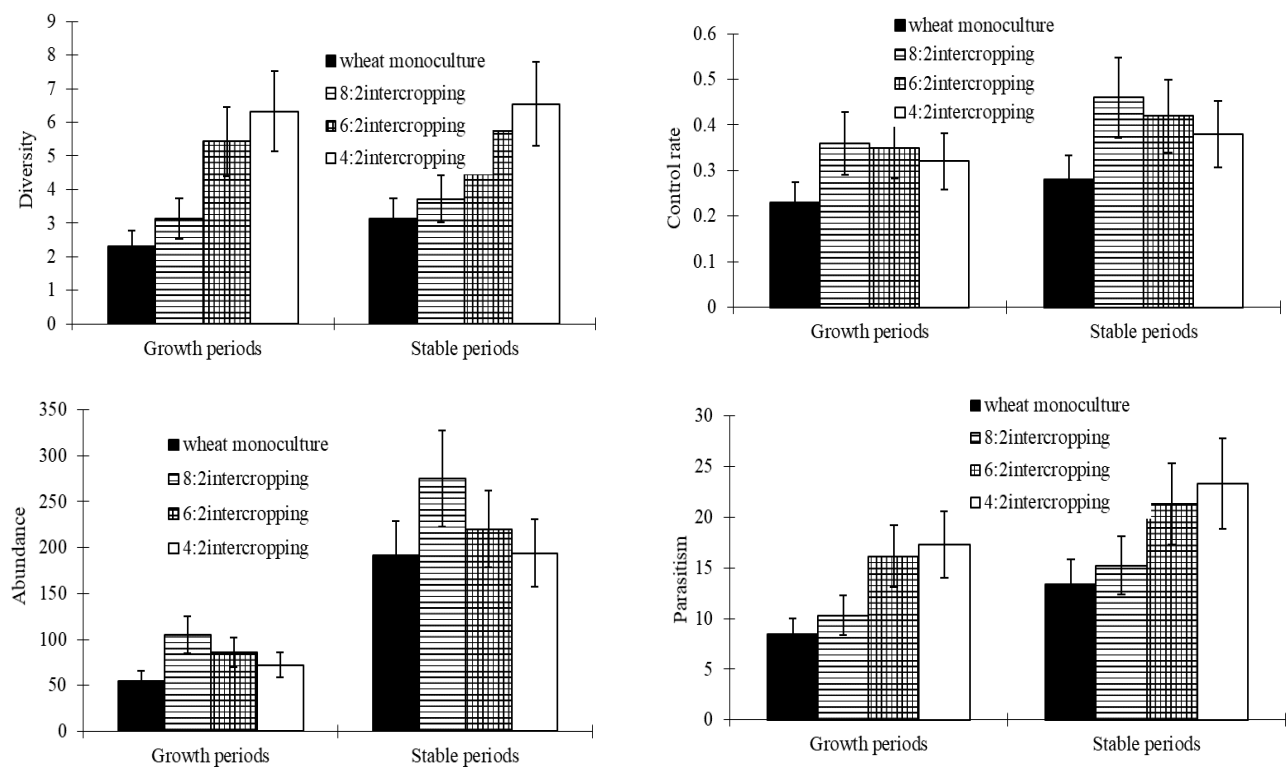

Figure 4. Effects of the wheat intercropping pattern on the communities of natural enemies and the control rate.

In the agricultural landscape, the proportion of wheat affected the distribution of wheat aphids and of its predators deeply. Owing to slower growth of maize in the prophase and maize planting area in bare land, the larger the proportion of wheat, the higher the proportion of bare land in the prophase. From the analysis of immigration quantity of winged wheat aphids, the lower the proportion of wheat, the larger the immigration quantity of winged wheat aphid. There was a weakly-positive correlation of wheat aphid mixed population's max population density with wheat's proportion. With the rise of the wheat planting proportion, the wheat aphid mixed population's max population density increased. The diversity of the wheat aphids' natural enemies decreased with the increase of the wheat planting proportion (Figure 5). 

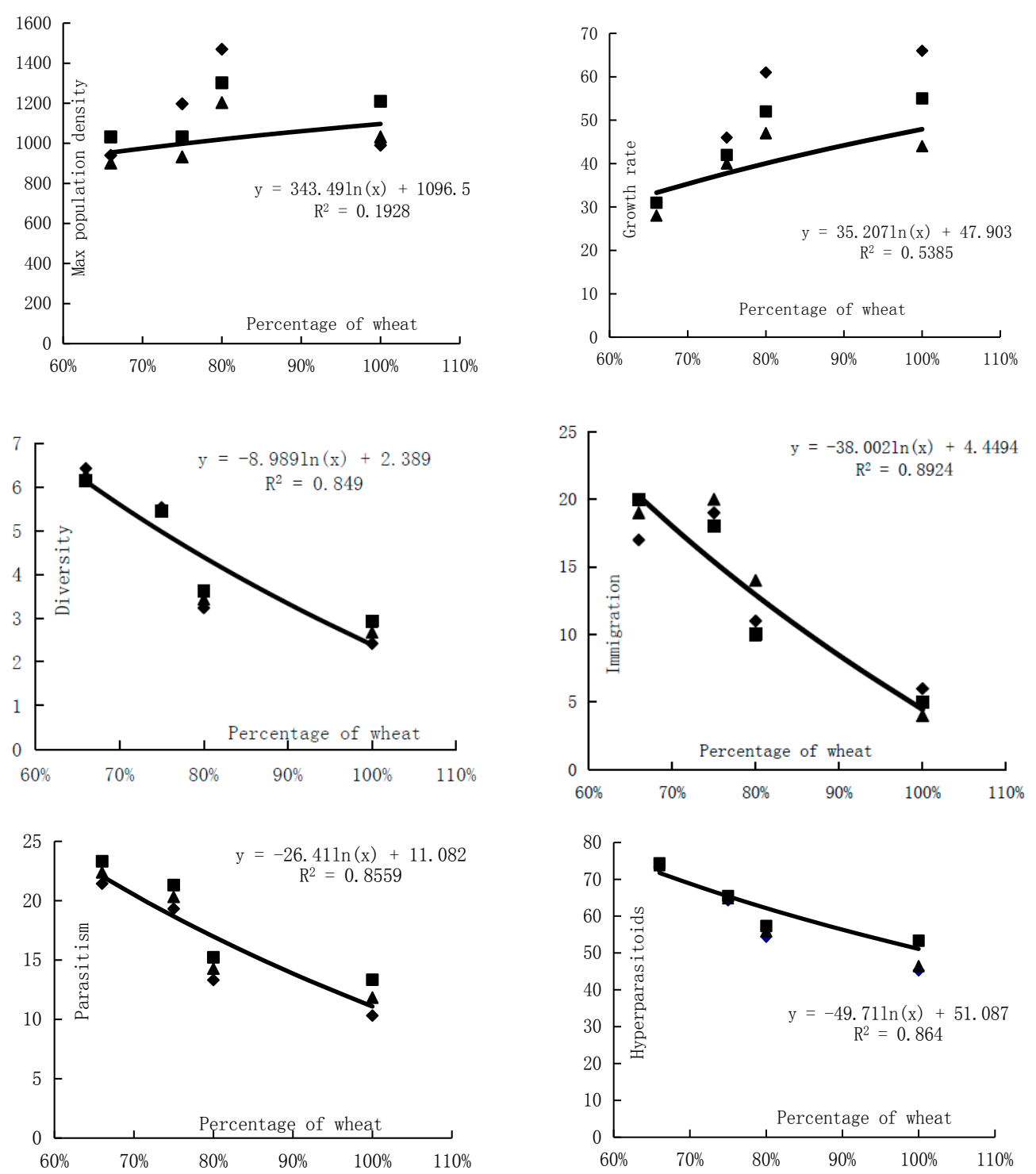

Figure 5. Effects of wheat patterns for communities of natural enemies and the control rate.

\subsection{Effects of Intercropping and Host Density on Wheat Aphids' Natural Enemies}

Compared to low host density, high host density showed significantly larger populations of all three types of natural enemies, i.e., primary parasitoids, hyperparasitoids, and predators, in both wheat monoculture and intercropped wheat. Meanwhile, compared with the wheat monoculture, the intercropped wheat had significantly larger populations of primary parasitoids and predators under both low and high host densities, but insignificant differences in hyperparasitoid populations at both low and high host densities (Tables 2-5).

A. avenae and A. gifuensis were the dominant species and occupied $77.71 \%$ and $15.16 \%$, respectively, of the total primary parasitoids. The host density effect on dominant species was very obvious, and the non-dominant species also showed a significant host density effect $(\mathrm{F}=110.32, \mathrm{df}=1,7, p=0.01)$. 
Table 2. Numbers and species of parasitoids in different host density and intercropping patterns.

\begin{tabular}{cccccc}
\hline \multirow{2}{*}{ Family } & Species & \multicolumn{2}{c}{ Low Host Density } & \multicolumn{2}{c}{ High Host Density } \\
\cline { 2 - 6 } & & Intercrop & Monoculture & Intercrop & Monoculture \\
\hline \multirow{5}{*}{ Aphidius avenae } & 257 & 198 & 425 & 309 \\
& A. gifuensis & 64 & 31 & 92 & 45 \\
& A. sichuanensis & 5 & 8 & 7 & 11 \\
& Lysiphlebus confusus & 5 & 2 & 7 & 4 \\
& Praon volucre & 4 & 1 & 4 & 2 \\
& P. orientale & 2 & 0 & 6 & 2 \\
& P. rhopalosiphum & 3 & 0 & 4 & 1 \\
& Trioxys asiaticus & 0 & 0 & 2 & 0 \\
\hline Aphelinidae & T. sp. & 0 & 0 & 2 & 2 \\
\hline
\end{tabular}

Table 3. Numbers and cpecies of predators in different host density and intercropping patterns.

\begin{tabular}{lccccc}
\hline \multirow{2}{*}{ Family } & \multirow{2}{*}{ Species } & \multicolumn{2}{c}{ Low Host Density } & \multicolumn{2}{c}{ High Host Density } \\
\cline { 3 - 6 } & & Intercrop & Monoculture & Intercrop & Monoculture \\
\hline \multirow{4}{*}{ Coccinellidae } & H. tredecimpunctata & 8 & 7 & 15 & 11 \\
& C. septempunctata & 7 & 6 & 13 & 11 \\
& H. variegata & 9 & 5 & 19 & 14 \\
\hline \multirow{2}{*}{ Syphidae } & Syrphus nitens & 9 & 6 & 12 & 9 \\
& S. cylindrica & 7 & 5 & 9 & 6 \\
\hline \multirow{2}{*}{ Chrysopidae } & Chrysopa sinica & 8 & 7 & 11 & 6 \\
& S. Croceolum & 5 & 2 & 7 & 3 \\
\hline \multirow{2}{*}{ Carabidae } & C. maderae & 4 & 7 & 13 & 7 \\
& S. terricola & 5 & 15 & 6 & 16 \\
\hline \multirow{2}{*}{ Lycosidae } & Chlaenius pallipes & 11 & 5 & 16 & 14 \\
\hline \multirow{2}{*}{ Linypiidae } & Lycisa coelestris & 7 & 12 & 19 & 16 \\
\hline
\end{tabular}

Table 4. Numbers and species of hyper-parasitoids in different host density and intercropping patterns.

\begin{tabular}{cccccc}
\hline \multirow{2}{*}{ Family } & \multirow{2}{*}{ Species } & \multicolumn{2}{c}{ Low Host Density } & \multicolumn{2}{c}{ High Host Density } \\
\cline { 2 - 6 } & & Intercrop & Monoculture & Intercrop & Monoculture \\
\hline \multirow{2}{*}{ Charipidae } & Alloxysta sp. 1 & 59 & 48 & 142 & 101 \\
& A.sp. 2 & 29 & 17 & 58 & 34 \\
\hline \multirow{2}{*}{ Pteromalidae } & Pachyneuron aphidis & 83 & 62 & 146 & 119 \\
& Asaphes suspensus & 69 & 46 & 113 & 89 \\
& Asaphes vulgaris & 37 & 26 & 64 & 51 \\
\hline Encyrtidae & Pteromalidae sp. & 4 & 1 & 6 & 3 \\
\hline EuloPhidae & Tetrastichus sp. & 7 & 3 & 6 & 3 \\
\hline Megaspilidae & Dendrocerus carpenteri & 7 & 2 & 8 & 3 \\
\hline
\end{tabular}


Table 5. F-test of populations of aphids' natural enemies in various comparisons.

\begin{tabular}{ccc}
\hline \multicolumn{3}{c}{ Monoculture vs. Intercropping } \\
\hline \multirow{2}{*}{ Primary parasitoids } & Low host density & \\
& High host density & $\mathrm{F}=13.92, \mathrm{df}=1,7, p=0.01$ \\
\multirow{2}{*}{ Hyperparasitoids } & Low host density & $\mathrm{F}=15.32, \mathrm{df}=1,7, p=0.01$ \\
\hline \multirow{2}{*}{ Predators } & High host density & $\mathrm{F}=3.72, \mathrm{df}=1,7, p=0.31$ \\
& Low host density & $\mathrm{F}=3.72, \mathrm{df}=1,14, p=0.35$ \\
\hline \multirow{2}{*}{ Primary parasitoids } & High host density & $\mathrm{F}=9.84, \mathrm{df}=1,7, p=0.01$ \\
& Low Host Density vs. High Host Density & \\
\hline \multirow{2}{*}{ Hyperparasitoids } & Monoculture & $\mathrm{F}=24.12, \mathrm{df}=1,7, p=0.01$ \\
\hline \multirow{2}{*}{ Predators } & Intercropping & $\mathrm{F}=48.32, \mathrm{df}=1,7, p=0.01$ \\
\hline & Monoculture & $\mathrm{F}=43.23, \mathrm{df}=1,7, p=0.01$ \\
& Intercropping & $\mathrm{F}=38.32, \mathrm{df}=1,7, p=0.01$ \\
\hline
\end{tabular}

\subsection{Effect of Intercropping on Wheat Aphids' Natural Enemies}

Intercropping had a greater effect on the predators of wheat aphids $(\mathrm{F}=14.25, \mathrm{df}=1,7, p=0.01)$. During the growth periods, the wheat aphid predator populations were highest in 8:2 intercropping, followed by $6: 2$ and 4:2 intercropping, with the lowest level in monoculture wheat. During the stable periods, the number of wheat aphid predators in intercropped wheat was higher than that in monoculture wheat. The population of wheat aphid predators was highest in 8:2 intercropping, followed by 6:2 and 4:2 intercropping, with the lowest number of predators in monoculture wheat (Figure 6).

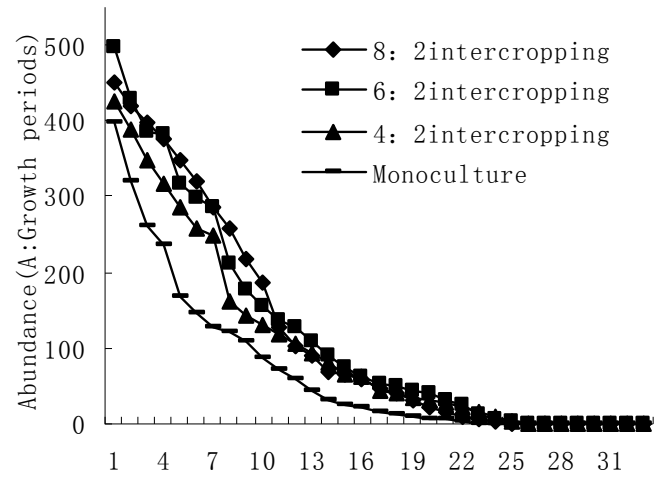

(A)

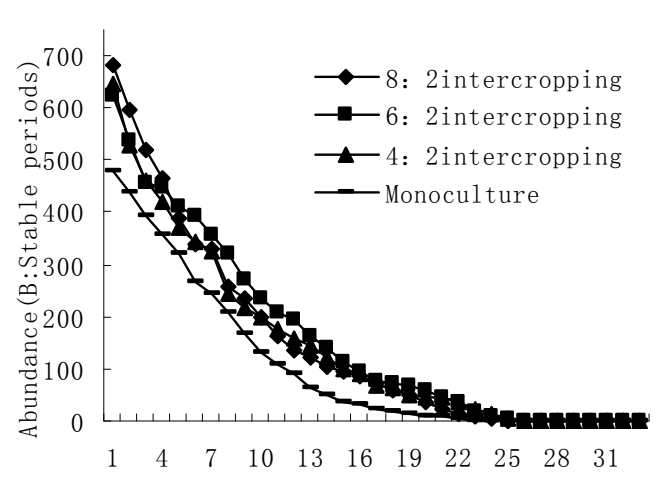

(B)

Figure 6. Effect of growth periods (A) and stable periods (B) in four intercropping patterns (e.g., 8:2, $6: 2$, and 4:2 intercropping, and monoculture wheat) on the abundance of aphids and their natural enemy diversity.

There were significant differences in the diversity of wheat aphid predators between intercropped wheat and monoculture wheat. Heterogeneous intercropped wheat had the highest diversity index, far more than that in the other types of wheat cultivation. Differences between monoculture wheat in the heterogeneous agricultural landscape and intercropped wheat in the homogeneous agricultural landscape were not observed. The lowest diversity index of monoculture wheat was observed in the in homogeneous agricultural landscape. From the analysis of predator diversity during wheat aphid growth periods (Figure 7A), the diversity index of omnivorous predators was the highest, 
$3.78 \pm 0.22$, in intercropped wheat in the heterogeneous agricultural landscape, followed by $3.21 \pm 0.23$ in monoculture wheat in the heterogeneous agricultural landscape and, furthermore, by intercropped wheat and monoculture wheat in the homogeneous agricultural landscape. All kinds of predators' diversity indices were higher, and the diversity of predators in intercropped wheat was higher than that in monoculture wheat. From the analysis of predator diversity during the wheat aphids' stable periods (Figure 7B), the pattern of predator distribution was almost consistent with that in the growth periods. The diversity of predators was higher in the heterogeneous agricultural landscape and in intercropped wheat. In general, the diversity index of wheat aphids' omnivorous predators was the highest, followed by multifeeding natural enemies, oligophagous predators, polyphagous predators, and monophagous predators.

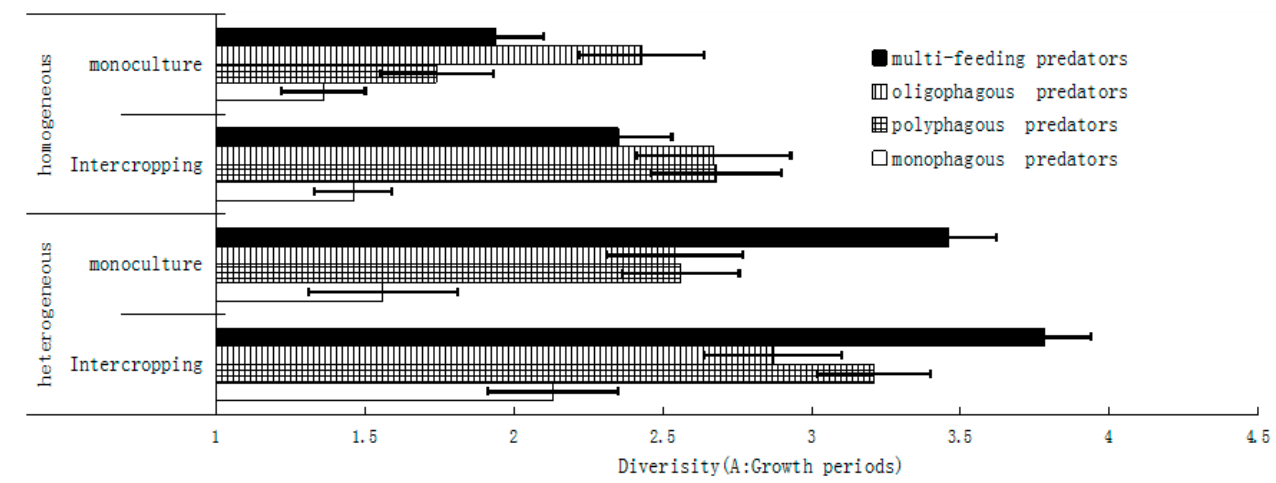

(A)

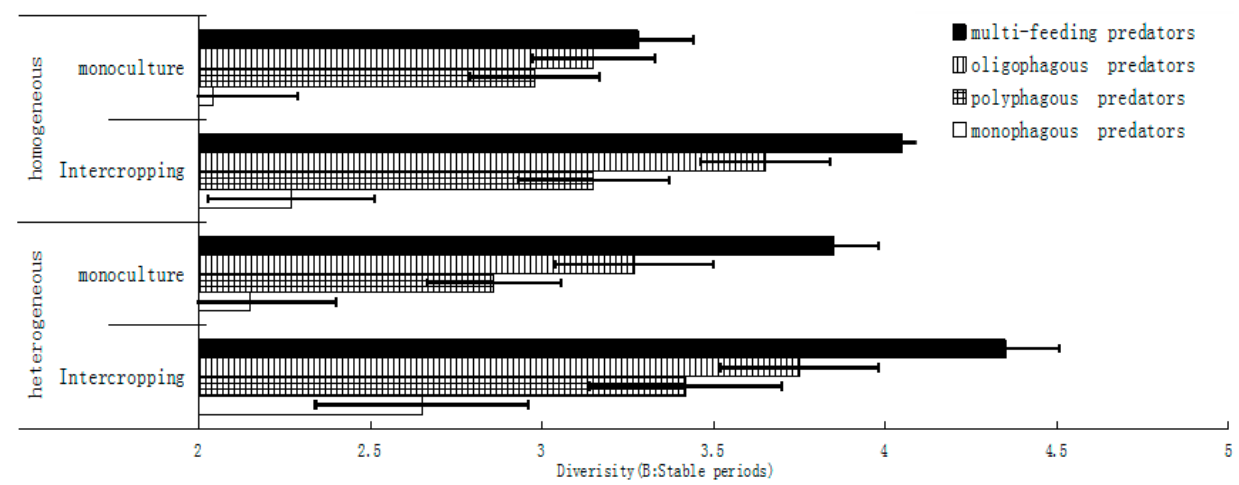

(B)

Figure 7. Effect of growth periods (A) and stable periods (B) in intercropping and monoculture patterns on the abundance of heterogeneous and homogenous natural enemy diversity while considering the multi-feeding, oligophagous, polyphagous, and monophagous predators.

\subsection{Interactions between Host Density and Intercropping on Wheat Aphids' Natural Enemies}

Based on the analysis of growth periods, host density, intercropping and their interactions had great effects on wheat aphids' parasitic natural enemies and predatory natural enemies (Figure 8). Host density had great effects on parasitic natural enemies $(\mathrm{F}=6.32 \mathrm{df}=1,7, p=0.05)$ and on predatory natural enemies $(\mathrm{F}=34.23, \mathrm{df}=1,7, p=0.01)$. Intercropping had great effects on parasitic natural enemies $(\mathrm{F}=15.43, \mathrm{df}=1,7, p=0.01)$ and on predatory natural enemies $(\mathrm{F}=19.23, \mathrm{df}=1,7$, $p=0.01$ ). The wheat aphids' host density and intercropping had weaker effects on parasitic natural enemies and predatory natural enemies (Figure 7). Host density accounted for $21.45 \%$ of the variation in parasitic natural enemy populations, and intercropping accounted for $43.54 \%$ of that. Overall, the diversity index value was highest for omnivorous natural enemies in wheat fields, followed by predatory predators, dietary predators, and predatory enemies. The interaction between host density 
and intercropping was $16.54 \%$, and other unknown reasons accounted for $19.47 \%$. Host density, intercropping, interactions, and other unknown reasons were slightly different in their effects on predatory natural enemies and accounted for $15.48 \%, 42.85 \%, 11.46 \%$, and $30.21 \%$, respectively.

The analysis of stable periods showed that they were almost consistent with growth periods. Intercropping had the most significant effect on the predators of wheat aphids. Parasitic natural enemies and predatory natural enemies accounted for $45.81 \%$ and $47.12 \%$, respectively. The next most important effect was that of host density. Parasitic natural enemies and predatory natural enemies accounted for $28.43 \%$ and $21.34 \%$, respectively. The interactions between host density and intercropping were weaker, accounting for $12.5 \%$ and $22.01 \%$, respectively (Figure 8 ).

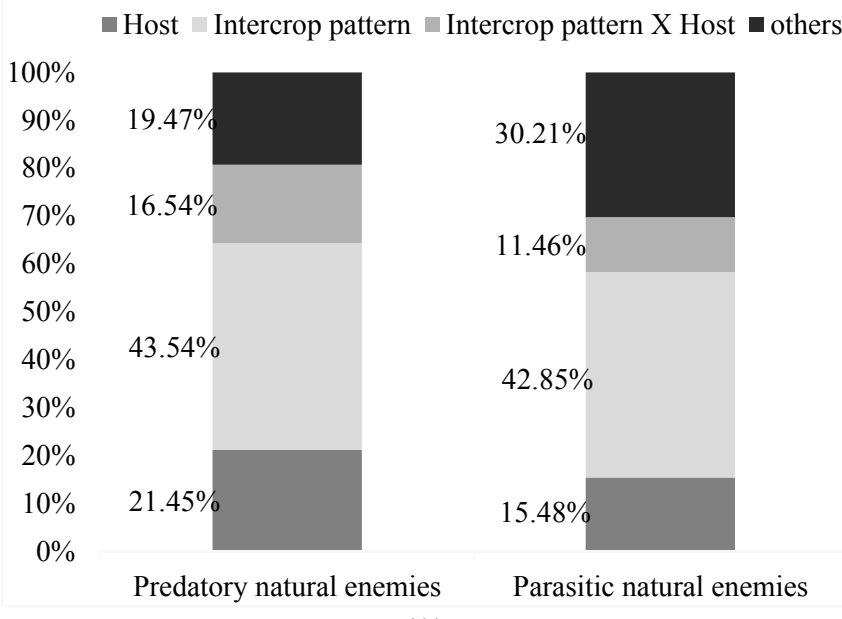

(A)

$\square$ Host $\llbracket$ Intercrop pattern $\square$ Intercrop pattern X Host $\llbracket$ others

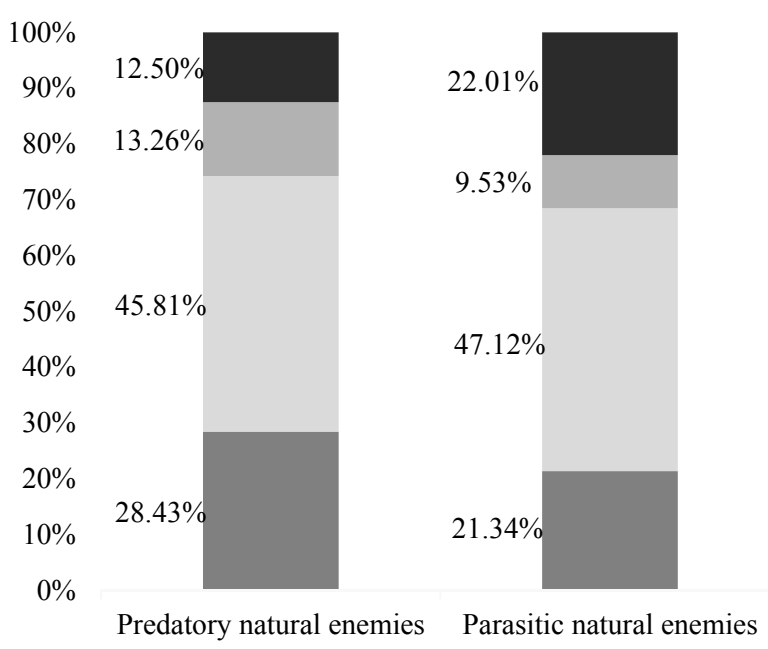

(B)

Figure 8. Effect of growth periods (A) and stable periods, and (B) on predatory and parasitic natural enemies while considering the percent density for host, intercrop pattern, intercrop pattern $\times$ host, and others.

\section{Discussion}

\subsection{Effects of Intercropping on Wheat Aphid Populations}

In wheat-maize intercropping, the quantity of immigrating winged wheat aphids was far higher than that in wheat monoculture during the immigration period. The quantity of winged aphids 
in intercropped wheat was even 20 to 30 times higher than that in monoculture wheat. However, the population growth rate in intercropped wheat was lower than that in monoculture wheat during the growth period. Although the quantity of winged aphids in monoculture wheat was low in the early period, the population growth rate was faster and easily formed a local population explosion, which may have disastrous consequences. During the stable period, the wheat aphid population in monoculture wheat was the highest, and it was slightly lower in intercropped wheat. However, there was no significant difference.

Intercropping has a great effect on wheat aphid population dynamics. The reason may be that the proportion of bare land was higher in intercropped wheat during the immigration period. Since early maize germinates later in wheat-maize intercropping, winged wheat aphids begin to grow slowly after their immigration period. Bare land is one of the important factors increasing the quantity of winged wheat aphids.

\subsection{Effects of Intercropping on Populations of Wheat Aphids' Natural Enemies}

Intercropping greatly affects the populations of wheat aphids' natural enemies. Wheat-maize intercropping can greatly increase the distribution of natural enemy populations and especially promotes parasitoid populations. The effect of parasitic wasps on the rate of wheat aphid parasitism in intercropped wheat was much higher than that in monoculture wheat. The rest of the predatory natural enemies were more evenly distributed in the intercropped wheat. Only a few species were more evenly distributed in the monoculture crop.

Although the wheat aphid parasitism rate was closely related to the density of hosts, intercropping can enhance the diversity of natural enemies, especially in the heterogenous agricultural landscape. A variety of intercropping patterns can improve the diversity of natural enemies and increase the effect of biological prevention and control. However, some other studies have confirmed that an increase in the diversity of natural enemies is not obvious in association with intercropping. The previously-studied agricultural landscapes may be the primary cause for this contradiction. In addition, the selection of the species used in intercropping may also be one of the most important factors affecting the distribution of natural enemy populations. Providing better shelters and rich food resources for plant species may be able to increase the biological prevention and control provided by natural enemies. However, providing pests with alternative host plants may reduce the effect of biological prevention and control. The key is the selection of plants and intercropping.

Therefore, we put forward the following points on intercropping: (1) Plant species that are conducive to natural enemies should be selected, and those that are beneficial to pests should be avoided. There is also a need to study the biological ecology of all kinds of natural enemies and pests. (2) Intercropping research needs to achieve two goals. The first is to improve land productivity. The second is to improve the biological prevention and control effects of natural enemies. (3) Based on the level of landscape research, the agricultural landscape background is sometimes the basic cause for an improvement in biological prevention and control. A good background can maximize the effects of biological prevention and control. If the agricultural landscape background is bad, biological prevention and control are impossible.

\section{Summary}

Increasing crop diversity is one of the important means for increasing the diversity of natural enemies of pests in farmland. Higher plant diversity can cause complex visual and olfactory stimuli for pests and, thus, interfere with their search for hosts and their spread and migration in farmland. Higher plant diversity is able to provide natural enemies with alternative hosts and more abundant resources, and creates favorable conditions for maintaining natural enemy populations and improving the effects of biological prevention and control. In this paper, the results showed that the population density of $M$. avenae in the intercropped wheat is lower than that in monoculture wheat. However, in the early stages, the M. avenae population density is higher in the intercropped wheat. In addition, 
especially in the immigration periods, the quantity of immigrating $M$. avenae in the intercropped wheat was obviously higher than that in the wheat monoculture and formed a strong positive correlative relationship with the proportion of wheat. According to the appropriate/inappropriate landing hypothesis, when the wheat aphid passes by bare land, the reflective light visually stimulates the wheat aphid to take the initiative to fall, which caused the wheat aphid population to be higher in the early period of wheat intercropping. As the maize matured, the advantage of plant diversity was more obvious. The maximum population density of $M$. avenae in the intercropped wheat was significantly lower than that in the wheat monoculture. In addition, the advantage of 8:2 intercropping was very obvious, which was the best pattern for improving biological prevention and control. Based on the influence of the main natural enemies, the populations of predatory natural enemies and parasitic wasps in the intercropped wheat were higher than those in monoculture wheat. The diversity of natural enemies can be significantly improved by 8:2 intercropping. There were no significant differences among the other three intercropping patterns. The populations of parasitic wasps in 6:2 intercropping were higher than those in monoculture wheat. However, the difference was not significant. The other three patterns had significantly higher populations than those in wheat monoculture. The natural enemies in the intercropped wheat were more diverse, and their abundances were higher than those in the wheat monoculture. This was consistent with the patterns reported in intercropping agroecosystems, showing more abundant and diverse pests than monoculture systems. Predators usually have multiple feeding habits, and their ecological niches are wider, which can allow them to play a better role in biological prevention and control in intercropped wheat. Parasitoid wasps, which have a single feeding habit, occur more sporadically.

The literature indicates that intercropping complexity is positively correlated with the parasitism rate. In our experimental study, host density was positively correlated with the primary parasitism rate and the repetitive parasitism rate. Intercropping also had a strong influence on the distribution of the populations of primary parasitoids [17-19,21]. Most studies did not divide the host density for analysis. The different parasitoid wasps had different reactions to changes in host density. These different reactions may be related to the long-term formation of evolutionary mechanisms as a response to the whole parasitoid wasp community competing for the same resources in the same space and time. The authors of this paper think that the evolution of primary parasitoids and hyperparasitoids are greatly influenced by the complexity of intercropping and are closely related to the plant species involved in intercropping, especially the flowering plants. These plants can provide pollen, nectar, and suitable microclimates for parasitic insects, even becoming shelters or hibernacles after disturbance of the farmland habitat. Of course, the relationship between these plants and parasitoid wasps was specific. Identifying the relationships between primary parasitoids and these specific plants, and eliminating the specific plants that provide resources for hyperparasitoids, may be an important research direction for protective biological prevention and control in the future. Therefore, studies regarding the landscape patterns of plant species, the densities of non-crop plants and phenological phases have more important significance for the diversity and function of parasitoid wasp communities.

Acknowledgments: We are grateful to Feng Ge and Dahan He for their critical and insightful comments on an earlier draft of the manuscript. We thank D. M. Mager for English editing of the manuscript. We also thank the farmers who allowed us to use their fields for the investigations. Financial support came from the Henan Province Science and Technology Projects (132102110021, 142300410007, 142102110028).

Author Contributions: Junhe Liu, Mingfu Yu, and Zihua Zhao conceived and designed the experiments, Junhe Liu and Yan Yan performed the experiments, Yan Yan, Zihua Zhao and Ningtao Wang analyzed the data, Junhe Liu, Abid Ali, Zihua Zhao, Mingfu Yu and Ningtao Wang wrote the paper; Ningtao Wang and Abid Ali modified the paper. All authors have read and approved the final manuscript.

Conflicts of Interest: The authors declare no conflict of interest 


\section{References}

1. Li, S.-J.; Liu, A.-Z.; Ru, T.-Q.; Wu, Y.-Q.; Han, S. Effects of different intercropping models on wheat aphids and their predator communities. Acta Agric. North China 2007, 22, 141-144.

2. Clough, Y.; Kruss, A.; Tscharnthe, T. Local and landscape factors in differently managed arable fields affect the insect herbivore community of a non-crop plant species. J. Appl. Ecol. 2007, 44, 22-28. [CrossRef]

3. Ferguson, A.W.; Barari, H.; Warner, D.J.; Campbell, J.M.; Smith, E.T.; Watts, N.P.; Williams, I.H. Distributions and interactions of the stem miners Psylliodes chrysocephala and Ceutorhynchus pallidactylus and their parasitoids in a crop of winter oilseed rape (Brassica napus). Entomol. Exp. Appl. 2006, 119, 81-92. [CrossRef]

4. Elliott, N.C.; Kieckhefer, R.W.; Lee, J.H.; French, B.W. Influence if within-field and landscape factors on aphid predator populations in wheat. Landsc. Ecol. 1998, 14, 239-252. [CrossRef]

5. Elliott, N.C.; Kieckhefer, R.W.; Michels, G.J.; Giles, K.L. Predator abundance in alfalfa fields in relation to aphids, within-field vegetation, and landscape matrix. Environ. Entomol. 2002, 31, 253-260. [CrossRef]

6. Elliott, N.C.; Tao, F.L.; Giles, K.L.; Kindler, S.D.; French, B.W.; Greenstone, M.H.; Shufran, K.A. Ground beetle density in Oklahoma winter wheat fields. Southwest. Entomol. 2006, 31, 121-128.

7. Macfadyen, S.; Gibson, R.; Raso, L.; Sint, D.; Traugott, M.; Memmott, J. Parasitoids control of aphids in organic and conventional farming systems. Agric. Ecosyst. Environ. 2009, 133, 14-18. [CrossRef]

8. Maes, D.; Dyck, H.V. Habitat quality and biodiversity indicator performances of a threatened butterfly versus a multi-species group for wet heathlands in Belgium. Biol. Conserv. 2005, 123, 177-187. [CrossRef]

9. Qiu, S.-B.; Yang, H.-W. Biological control, an important technology in integrated pest management. Plant Prot. 2007, 33, 1-6.

10. He, D.-H.; Zhao, Z.-H.; Zhang, D.-H. Responses of insect communities and populations on habitat fragmentation in grassland landscapes. Acta Pratacult. Sin. 2009, 18, $235-241$.

11. Muthukumar, M.; Sharma, R.K. Eco-friendly management of insect pests of cauliflower (Brassica oleracea var. botrytis) with intercropping and botanicals. Indian J. Agric. Sci. 2009, 9, 135-137.

12. Ma, K.Z.; Hao, S.G.; Zhao, H.Y.; Kang, L. Strip cropping wheat and alfalfa to improve the biological control of the wheat aphid Macrosiphum avenae by the mite Allothrom biumovatum. Agric. Ecosyst. Environ. 2007, 119, 49-52. [CrossRef]

13. Zhou, H.-B. Study on the Effect Using Wheat-Pea Intercropping and Varieties Diversity Ecological Regulation on Sitobion avenae and Its Mechanism. Master's Thesis, Shandong Agricultural University, Tai'an, China, 2009.

14. Zhou, H.-B.; Chen, J.-L.; Liu, Y.; Chen, D.-F.; Chen, L.; Sun, J.-R. Using genetic diversity of wheat varieties for ecological regulation on Sitobion avenae. Acta Phytophylacica Sin. 2009, 36, 151-156.

15. Zhou, H.-B.; Chen, L.; Chen, J.-L.; Chen, D.-F.; Liu, Y.; Sun, J.-R. Effect of intercropping between wheat and pea on spatial distribution of Sitobion avenae based on GIS. Sci. Agric. Sin. 2009, 42, 3904-3913.

16. Zhou, H.-B.; Chen, J.-L.; Chen, D.-F.; Liu, Y.; Sun, J.-R. Effects of wheat-pea intercropping on the population dynamics of Sitobion avenae (Homoptera, Aphididae) and its main natural enemies. Acta Entomol. Sin. 2009, 52, 775-782.

17. Huang, D.-C.; Zhang, R.-Z.; Dong, Z.-K.; Gao, F.-J.; Pan, G.-Y.; Ouyang, Z. Multi-population dynamics of aphids and natural enemies on winter wheat and forages and their relationships. J. Environ. Entomol. 2008, 30, 325-330.

18. Wang, W.-L. The Control Effect of Wheat Biodiversity on Wheat Filed. Master's Thesis, Shandong Agricultural University, Tai'an, China, 2008.

19. Wang, W.-L.; Liu, Y.; Ji, X.-L.; Zhou, H.-B. Effects of wheat-oilseed rape or wheat-garlic intercropping on the population dynamics of Sitobion avenae and its main natural enemies. Chin. J. Appl. Ecol. 2008, 19, 1331-1336.

20. Zhao, Z.-H.; He, D.-H.; Hui, C. From the inverse density-area relationship to the minimum patch size of a host-parasitoid system. Ecol. Res. 2012, 27, 303-309. [CrossRef]

21. Liu, Q.; Zhang, T.-W.; Liu, C.-Z. Effect of Inter-cropping of Wheat with different crops on occurrence quantity of wheat aphid. Guizhou Agric. Sci. 2010, 38, 148-149.

22. Finch, S.; Collier, R.H. Host plant selection by insects, a theory based on 'appropriate/inappropriate landings' by pest insects of cruciferous plants. Entomol. Exp. Appl. 2000, 96, 91-102. [CrossRef]

23. Shen, J.-H.; Nie, Q.; Huang, D.-R.; Liu, G.-J.; Tao, L.-X. Recent advances in controlling plant diseases and insect pests by mixture planting ang inter-panting of crops. Acta Phytophylacica Sin. 2007, 34, 209-216. 
24. Liu, J.-H.; Yu, M.-F.; Abid, A.; Liu, J.-Y.; Li, K.M.; Niaz, H.K. Density estimation of ground dwelling predators in wheat fields of northwest China. Pak. J. Zool. 2016, 47, 21-29.

25. Gagic, V.; Tscharntke, T.; Dormann, C.F.; Gruber, B.; Wilstermann, A.; Thies, C. Food web structure and biocontrol in a four trophic level system across a landscape complexity gradient. Proc. Biol. Sci. 2011, 278, 2946-2953. [CrossRef] [PubMed]

26. Lohaus, K.; Vidal, S.; Thies, C. Farming practices change food web structures in cereal aphids-parasitoid-hyperparasitoid communities. Oecologia 2013, 171, 249-259. [CrossRef] [PubMed]

27. Brewer, M.J.; Elliott, N.C. Biological control of cereal aphids in North America and mediating effects of host plant and habitat manipulation. Annu. Rev. Entomol. 2004, 49, 19-242. [CrossRef] [PubMed]

28. Schmidt, M.H.; Roschewitz, I.; Thies, C.; Tscharntke, T. Differential effects of landscape and management on diversity and density of ground-dwelling farmland spiders. J. Appl. Ecol. 2005, 42, 281-287. [CrossRef]

29. Pertz, O.; Hodgson, L.; Klemke, R.L.; Hahn, K.M. Spatiotemporal dynamics of RhoA activity in migrating cells. Nature 2006, 440, 1069-1072. [CrossRef] [PubMed]

(C) 2017 by the authors. Licensee MDPI, Basel, Switzerland. This article is an open access article distributed under the terms and conditions of the Creative Commons Attribution (CC BY) license (http:/ / creativecommons.org/licenses/by/4.0/). 